\title{
Timescapes of the Network Society
}

\author{
Robert Hassan
}

Since the late " 70 s, the mutually reinforcing interaction between neoliberal economics and the revolution in information and communication technologies (ICTs) has transformed the world in many ways. "Globalization" is what we have come to call this process, and many aspects of its profound effect have been analyzed from a range of perspectives (e.g. Appadurai 1990; Robertson 1993; Omahe 1993; Waters 1995; Bauman 1998; Steger 2003). This paper discusses a central element of this change through globalization that has so far received relatively little attention-our relationship with time and how this is changing, in turn, the nature of power and politics. More particularly, it looks at these changing dynamics of time, power and politics through the nexus between neoliberalism and the ICT revolution and the emergent network society that this process has created.

\section{Time in Theory}

Until recently, the study of time in the social sciences and social theory has suffered a more generalized neglect; it has tended to occupy a peripheral role as a method through which modernity was understood. In other words modernity has not been analyzed systematically from what Barbara Adam calls a "temporalized perspective" (2003). Marx, for example, did not articulate an explicit theory of time and wrote only sporadically about the role of the clock in the commodification of labour (see Lukacs, 1990: 89-91). In the 20th century Lewis Mumford did in fact see the clock as "central to the Industrial Revolution" but this was in the context of a discussion on the general role of technology and technical systems, not temporality per se (1934/1967:14). Social historians such as E.P. Thomson (1967/1993:352-403) likewise attributed a good deal of importance to the clock as a transformative technology in the context of an unfolding modernity. However, it is viewed principally as a rationalizing technique of worker "time discipline" and not as a way to understand what this temporal domination may mean for the diversity of human time reckoning prior to their colonization by the industrial logic of the clock.

Paul Virilio, in his more speculative social theory of temporality, concentrates on the (very real) effects of speed and velocity in politics and in social life (Virilio 1986; 2000). Others have grappled with how our time-space horizons are being drastically curtailed in the era of "flexible accumulation." David Harvey, for example, in his Condition of Postmodernity (1989) sensed that our relationship with time and space were undergoing profound change due to the revolutions of neoliberalism and ICTs. He called this "time-space compression" and, tantalizingly, writes that it will "revolutionize the objective qualities of space and time [so] that we are forced to alter...how we represent ourselves to the world" (1989: 240). Unfortunately, however, Harvey fails to do full justice to this claim and concentrates his theoretical explorations much more upon the spatial dimension at the expense of the temporal. The "rapidity of time," as he terms it, makes it difficult to "react to events" (1989:305-6), but the analysis does not proceed much beyond this fairly obvious conclusion, and discussion on ways to locate in theory and harness in practice the "objective quality" of postmodern time is not attempted. In fairness, Harvey was writing in the opening phases of the transition from Fordism to network-based flexible accumulation, and his undoubted prescience should not be expected to achieve total perspicacity.

The changing temporal organization of everyday life within the postmodern network society is the key issue 
this article seeks to examine. To explore this question more fully, some central questions need to be considered. These are: how do we experience time? What is the nature of time in the network society? How does it contrast and compare with our relationship with clock time, an abstract and empty social construction that has dominated our relationship with time since the industrial revolution? And, finally, what does what I term "network time" portend for what Barbara Adam (1998) terms "timescapes" - times that interpenetrate and permeate our lives but have been displaced, marginalized and sublimated by industrial clock time? Let us begin with some grounding perspectives on time from recent social theory.

\section{| Timescapes in Social Life}

How do we experience time? Today from most people the question would elicit a negative answer. We are "pressed" for it; our time is "squeezed" to the point where we have little left to ourselves, and so forth. Beyond this generalized frustration with "it," most of us delve no further into its nature-just like the ever more complex realms of modern life, we feel there's simply "no time" to go into such matters. However, a diversity of time(s) or temporalities are immanent in both humans and nature. Potentially, we can experience and live in an interconnecting multiplicity of times that can combine in an endlessly complex but ultimately unified temporal whole. As I said, Adam has called these temporal dimensions "timescapes." But what are these timescapes? Unfortunately, modern English is a limited tool with which to describe, accurately, these immanent temporalities that we barely understand and so much more work needs to be done to overcome this. Perhaps an easily comprehended way to think about timescapes is to think of an array of temporal features-flowing durational "scapes" — that exist in lived reality, in us, in our cultures and in nature. Each feature, or temporal scape is implicated in all the others but not necessarily of equal importance. Context is the "now" or the "present." It is the intersecting point of contact between the different timescapes that touch our lives_-or those timescapes that we ourselves bring to a context or situation to generate a uniquely experienced timescape. As Christopher Prendergast puts it: "What we call 'the present' is a dynamic cluster of temporal traces, of the past it has been and the future it is in the process of becoming" (2003:99). What we create and experience in "the present" is, in effect, a timescape that is part of a socially constituted temporal whole, part of what is to be alive in a becoming and emergent social world.

Adam (2004) has succeeded in stretching the capacity of the language towards a useful taxonomy of the timescapes in humans and in nature. She argues that timescapes comprise such things as "tempo," which is speed, pace, intensity; "timing," which is synchronization; "time point" which is moment, now, instant, juncture; "time patterns" which is rythmicity, periodicity, cylicality; and "time extensions" which are duration, length, continuity. These temporalities are context- and culture-generated and are subject to constant change through the diversity of human circumstances.

For the peoples and cultures of pre-modernity, the diversity of temporalities were lived and experienced more directly, through less forms of mediation. Like breathing, they were explicit elements of life. People experienced them more proximately because they were creating their own living timescapes just as much as they produced their own forms of space, or landscapes (Lefebvre 1991; Gosden 1994). It was noted that timescapes are profoundly social and cultural. They are also dialectical, emerging as practices through our interaction with each other and with the natural and built environments. As archeologist Christopher Gosden (1994: 34-5) put it:

People create time and space through their actions. Time and space, in turn, become part of the structure of habitual action, shaping the nature of reference between actions.

These took as many forms as there were social and cultural contexts to generate them, across the millennia and across the world. Timescapes could be cyclical, involving seasons, or rebirth; they could comprise linear conceptions of past, present and future; they could be cosmic, taking time patterns from the heavens; they could be "static" in that, through myth and ritual, cultures would seek to "arrest time" (Adam 2004). Or they could indicate an absence of time coupled, paradoxically, with its profound immanence, as found in elements of Zen Buddhism. For example, as American poet Robert Haas (1994: xi) has argued, the aim of the poetry of 17th century haiku master Matsuo Basho was to express that: "every moment is eternal; or, every moment of time is all time; therefore time doesn't exist." Moreover, these timescapes do not exist in isolation from each other- they "interpenetrate and permeate" the 
lives of their creators and experiencers (Adam 1995:12) in the ongoing evolution of culture- and context-generated timescapes. In pre-modernity these dynamics gave a diverse temporal dimension to whole ways of life, to ways of thinking (knowledge production), and how we express this through language and writing; and these, in their turn, also reflected the immanent temporalities through the communication of changes in tense and so on. In short, they provided the means to orient the individual and group temporally in the world and to give meaning to their place within it.

\section{| Potential Time and Power Time}

I said previously that we "potentially" are able to experience these immanent timescapes, and create an infinite diversity of others through culture and context. It is my contention that we still only vaguely intuit the timescapes of nature, of culture, of context and of our own biology, because they have been sublimated, displaced and dominated, to an ever-increasing degree-since at least the end of the Middle Ages-by industrialized clock time. From our contemporary perspective, it is difficult to appreciate the extraordinary effect that clock time has had upon modern and modernizing societies. And it is difficult to remember, so deeply has its logic impregnated cultures and societies, that it is not "time" at all but a social construction given the seal of scientific truth and validity through the revolution in Newtonian physics. According to this mathematical perspective, time exists not in nature and humans, but that these exist in time. Newton put the case famously in his 1687 Principia when he wrote that: "Absolute true and mathematical time, of itself, and from its own nature, flows equably without relation to anything external." He regarded moments of absolute time as moments that follow a continuous linear sequence. The rate at which these moments succeeded one another is independent of the universe and its processes (Whitrow 1972:128-9). The most powerful legacy of Newton's work was that it gave an abstract, mathematical and mechanistic foundation to perceptions of how the natural world and its place in the universe are constituted. Indeed, in keeping with the emerging thought of Enlightenment philosophy that advocated rational science and technological development as evidence of human progress, the machine, and in particular the clock, became a metaphor for the world and its logical, harmonious ordering. Clock time, then, from the perspective of modern social theory, reveals itself as a social creation, a figment of Enlightenment philosophy purporting to represent scientific actuality. Like the ill-fated Jacobin ten-day week that was legislated for during the early phase of the French Revolution, the clock is an abstract symbol for time; it is rationality pushed to an extreme, and an attempt at a machinic (clockwork) metering of the unruly and diverse timescapes that exist in humans and in nature.

However, clock time doesn't feel extreme, so inured to it have we become; so deeply has it infused our cultures and societies. This is because clock time, the revolutions in science and technology, and the capitalist system of production were mutually dependent factors in the industrialization process and the creation of modernity. These formidable logics came together in their most world-changing form through what Marx called "commodity production" and were expressed most succinctly in Benjamin Franklin's lapidary phrase "time is money" (Hassan 2003). The meter of the clock as scheduler and organizer of everyday life struck deeper and deeper into the world's cultures and societies as capitalism spread and suffused modernity in its wake. As the power of the clock grew, so too did the displacement, colonization and sublimation of the ever-changing, ever-fluid timescapes of millennia. The generation of potential time into actually lived timescapes through culture and context were increasingly thwarted by the power time of capitalist industrialism. Time metamorphosed in human experience from the local and the diverse, to the universal scope, the unerring meter and the undifferentiated context. This transformation was necessary to the world-historical mission of "commodity production" and the global rule of capital. As Éric Alliez put it: "only abstract time can ensure an effective function of capitalization" (1996:154). The time of the clock (relatively quickly) became what we perceived as time and experienced as time and what governed temporal life. In other words, a mechanized device that was imbued with transcendental significance, replaced the human and natural timescapes that has evolved over thousands of years. As clock time sublimated the timescapes of culture and context, it began to reshape modes of thoughts, ways of seeing and ways of perceiving the world. "Other" times became gradually relegated to the status of things we vaguely and inexplicably intuit. We see this meagerness of temporal perception in modernity through what Michael Flaherty calls "folk theory" or culturally bound ways of understanding the interpenetration of differing timescapes. For example, how is it, we have asked ourselves for millennia, that time seems to pass quickly when enjoying oneself, and "drags" when bored? Or does it? Flaherty shows how the logic 
of "folk theory" can easily be reversed in "highly eventful circumstances" such as in combat or in a traffic accident, where split-second events seem to last forever, the "my whole life flashed before my eyes" scenario that many people experience (1999: 21-22).

Over the nineteenth and twentieth centuries the rhythm of the clock has become so much part culture and society that we could hardly describe it in separation from other modes of life. It buries our relationship with these "other" times and frustrates a deeper understanding of them. The abstraction, to paraphrase Jürgen Habermas (1987:336), had become real.

Nonetheless, domination by the régime of clock time does not indicate that the times of pre-modern societies have to be seen as analytically and anthropologically distinct from those of modern ones. In both epochs the relationship with time are marked by complexity and potentiality. The critical difference is that in modern societies, as I have argued, a growing complexity of temporalities has become problematic and that time potentiality has been sublimated. As Alliez puts it "potential time" has been colonized (or as he more strongly puts it) "conquered," by "power time" (1996: xv). The process of colonization, however, does not mean that these timescapes have been nullified and voided by industrial power time. In society their presence is being constantly felt.

We can see this on the structural level, where the unerring meter of clock time that is necessary for the functioning of capitalism (and the clock time metering of cultures and societies to facilitate this) continually clashes with the timescapes of both humans and nature - often to catastrophic effect. The logic of capital and the clock constantly seek to synchronize the fluid and emerging temporal worlds of humanity and nature to its own measurethat of control, commodity and rationality. Harmeet Sawhney put the argument succinctly when he wrote, "[the] bygone world was a world of rhythms. Today, we live in a world of [attempted] synchronization" (2004:360). The differing timescapes in biology, in chemistry, in all organic life and in the environment, conflict with a rigidly clockentimed capitalism. The result is a "dischrony" that underscores what Ulrich Beck terms the "risk society" (1992). For example, we saw the effects of dischrony and risk recently and horribly in the slow-paced eruption of the bovine spongiform encephalopathy (BSE) disease in Britain in the 1990s (Adam, 1999). Here, the unchanging temporal imperatives of industrial agribusiness (acceleration, commodification, optimization) clashed with those of human and animal biology, rendering, so to speak, BSE an "invisible" risk that came to light only when the damage forced its way onto the scientific gaze and (later) a horrified public consciousness. A major consequence of this dischrony is that an increasingly complex industrial society is quite literally laying "time bombs" that will "explode" in times that are governed by the precise nature of the timescapes involved in the process. We can continue this literalism to furnish other illustrations. For example, the laying of landmines brings the open ended, complex and fluid timescapes of war (politics, ideology, weather, tactics, etc) into dischrony with industrially-entimed munitions production. The result, inevitably, is that war will end at some unknown point in the future, a point which the bomb makers must over-compensate for, ensuring that people will continue to be at risk from death and dismemberment for long after the timescapes of the conflict has passed. A similar logic is in operation in the manufacture of weapons-grade plutonium-293 for nuclear bombs. The Cold War, which triggered this process, lasted about fifty years (it could have lasted five, or five-hundred). Plutonium-293, however, will remain radioactive and lethal for about twenty-four thousand years.

This clash of human, biological, chemical and environmental timescapes with that of industrialized clock time ensures an increasingly risk-prone society. As industrialized society becomes more complex, then so too will the risk factor continue to increase. This is inevitable unless the time of the clock and capitalism can harmonize (work in cooperation with, not to seek control over) the deeper timescapes in nature and in humans. The emergence and potential of what I've termed network time may be one alternative to this increasingly problematic dischrony.

\section{Network Time}

At first glance "network time" does not seem too promising a basis upon which to pin one's hopes for our rediscovery of the diversity of times and rhythms that comprise the sublimated timescapes of modernity. Network time sometimes acts as a supposed synonym for the much more widely used term "real time," and this is usually associated with the technical obsession with temporal acceleration. These terms are differentiated, because I argue that "real time" is a fundamental misnomer, and that an understanding of what "network time" is opens up many more temporal possibilities. So let us briefly concentrate on the inapplicability of "real time" to describe temporality 
in the network society. Computer programmers and systems designers coined the term to describe operating systems that could respond at high-speed to the input of data. The computer technicians' online dictionary of Internet terms defines real time as something "occurring immediately"; and on a surface level at least, this is how most people would conceive of real-time. However, this generalized definition, stemming as it does from a technical perspective, sheds little light on the social, cultural and temporal implications that "occurring immediately" may signify. Michael Heim, in his The Metaphysics of Virtual Reality, gives a more intriguing definition. He writes that real-time is "Simultaneity in the occurrence and the registering of an event, sometimes called synchronous processing..." (1993: 157). This represents a significant shift from the technical definition. "Immediately" connotes a brief temporal lag (be it measured in minutes, seconds, or even nanoseconds), whereas "simultaneity" suggests "happening at the same time," a canceling-out of temporal duration between events. Simultaneity implies, then, a non-time, the shattering, or voiding, or "death" of time. A problem here is that social theorists and the media more generally, have taken the technician's term of indicating something that happens in digitally compressed clock time (fast, but still multidurational, multi-patterned, etc.) and implicitly or explicitly take it to mean no time. For example, Castells, in his 1996 book The Information Age: The Rise of the Network Society argues that globalization and the information age are heralding the era of domination by real-time, or what he calls "timeless time." Real time, for Castells, is also a kind of "non-time" which means that as the network society becomes more encompassing of culture and society, "linear, measurable, predictable time is being shattered...in a movement of extraordinary historical significance" (p433). In his speculative social theory, Paul Virilio is even more explicit when he writes in that "the teletechnologies of real time... are killing 'present' time by isolating it from its here and now, in favour of a commutative elsewhere that no longer has anything to do with our "concrete presence" in the world..."(1997: 10).

If we think about the nature of time, however, we can readily appreciate that the concepts of "timeless time" or of the "killing" of time, make no sense at all. Ontologically it is an impossibility. We are temporal beings living in a temporal environment-whether inside or outside the network. Temporal durations, patternings, rythmicities, suffuse everything, from the rapid heartbeat of a fetus in the womb to the several years it takes the oyster to grow its pearl from a grain of sand. Like trying to imagine "time before time began," i.e., before the Big Bang fifteen billion years ago, we evolved anthropologically and culturally ill-equipped to think in such terms. We may more readily appreciate the absurdity of simultaneous real time if we think about our own involvement with the network society. Think of the Internet. Its technical capacities and our own human capabilities ensure that this is an inherently asynchronous space. Nothing occurs instantaneously, or in real time. There is an open-ended spectrum of temporalities within the network, measured from a picosecond (one trillionth of a second) upwards. For example, we can flash an email across the world in seconds or minutes, and then wait for an unknowable period for a reply. This could come in seconds, minutes, hours, days, or never. Networks can fail, they can slow down or speed up; we could be using state-of-the-art technology, or an old 486 PC and a dial-up modem. The multiform temporal dimensions that we are able to create, at least in potential, in the Internet, has led Lee and Liebenau to note, “...we can regard the experience of using the Internet as one of pseudo-instantaneous access" (2000: 51).

One of the most significant developments in the evolution of the network society is that through our use of ICT technologies in more and more realms of life, we are creating a digitally based, spatial and temporal ecology. Through the Internet, through mobile phones, through PDAs, email, digital video and through a rapidly increasing density of interconnectivity by new applications and devices that appear almost every month, we are continually creating a diversity of spaces and times. These are network spaces and network times, for ourselves and for others to share. Just like the landscapes and timescapes created by humans in pre-modernity in the construction of their own context-dependent cultures and societies, contemporary denizens of the network construct their own informationbased ecology. Network time is a digitally compressed clock time, a "chronoscopic time," (see Hassan 2003) but it is a time that has exploded into a million different time fractions, as many time fractions as there are users with ICT applications, in the amorphous and constantly emerging network ecology. This is where the important break with the analogue meter of the clock occurs. Clock time has been made digital by computer technology and set loose in the creation of fluid networks of social interaction. In short, computing, the emergence of the network, and the actions of human agency have subverted the basis upon which the mechanical clock shaped and synchronized the modern world.

Technological developments promise to make this temporal transformation even more profound. For example, advances in nanocomputing, biocomputing and quantum computing techniques have challenged both the scale and the very basis upon which computing is predicated, and is set to make computing and the role of computers in life even 
more ubiquitous. Not only ubiquitous, but literally part of culture, society and the physical body. Nanocomputing is the construction of computing at the nanoscale (nanometer is one billionth of a meter, or one hundred-thousandth the width of a human hair). Working at this level, scientists at Bell Labs in the US have already constructed a transistor that is 50,000 times smaller than the width of a human hair (Brumfeil 2001). Shrinking down silicon chips in scale has physical limitations, of course, but this is being tackled through research in biocomputing, where computers are able to function like living organisms at the molecular or chemical level, obviating the need for silicon-based technology altogether. And spanning both these developments is the research in quantum computing. Here the whole basis upon which digital computing is founded (the binary logic of ones and zeros, on and off) is being changed. Working at the quantum level, where the classical laws of physics don't hold, engineers have discovered that in a quantum computer, classical binary logic operates simultaneously at both one and zero, on and off — at a state they call a superpositionwhich constitutes a fundamental revolution in the basic nature of information processing. Through these kinds of advances, the cyborg dream of Nicholas Negroponte (1995) to blend "bits with atoms" i.e., the fusing of computers with humans, seems to be a fast-approaching reality. Indeed, in 2001, Negroponte's brainchild, the MIT Media Lab, with funding from the American National Science Foundation, set up the Center for Bits and Atoms with the explicit aim to "explore how the content of information relates to its physical representation, from atomic nuclei to global networks" (MIT News, 2001).

Let us pause to summarize thus far. It is clear that through the information technology revolution something exceptional has occurred to the foundations of our modern relationship with time. Through ubiquitous computing and ever more dense levels of interconnectivity, the network society has evolved. This is both extraordinary and unprecedented, as it constitutes the creation (at least in potential) of a network environment; a network ecology that contains its own digitally created spaces and times. The evolution of asynchronous network time has meant that for the first time since the beginning of the industrial revolution, humans are able to create and experience timescapes that are not synchronized to, or sublimated by, the logic of the clock. This process is set to become yet more profound through developments in advanced computing. Humans, as active agents in an amorphous and emergent network ecology, will potentially be able to create their own timescapes. These will not be based upon or dominated by the abstract logic of the mechanical clock, but will be an asynchronous temporality that is predicated upon the interaction of innate human timescapes coupled (literally, as the active research into Negropontean cyborg theory shows) with molecular level computing.

Millions of people across the world who are part of the network society are already creating their own spaces and their own times, in their work, leisure and in interaction with each other in everyday life. However, the timescapes of genuine diversity of the kind Adam has cogently written are still immanent within the network society, not actually existing as real practice. Potential time has yet to overcome the domination of capitalist power time. But as I will argue, the "power-geometry" of space and time are in a state of deep flux at present, and historic opportunities present themselves for a social and cultural revolution in the dimensions of space and time in the network ecology. In these final two sections I will lay out the scope of the problem as well as the range of opportunities that are available for humans to overcome the domination of the clock and to recover and create anew the experience of diversity of timescapes that are immanent in both us, and the environments with which we interact.

\section{| The Temporal Geometry of Power in the Network Society}

As noted at the beginning of this essay, the network society evolves and grows directly out of the nexus between neoliberal capitalism and the revolution in information and communication technologies. Globalization is first and foremost and process of spatio-temporal power relations. It is, as Doreen Massey puts it, a relationship of powergeometry $(1991 ; 1994 ; 1999)$. The term neatly captures how power works in a complex and interconnected global matrix. Power, she argues, is generated through the specific geometries of connections, of proximities, of relationship building, of networks of influence and so on. She writes that:

Different social groups, and different individuals, are placed in very distinct ways in relation to these flows and interconnections. At the end of all the spectra are [...] the jet setters, the ones sending and receiving the faxes and the e-mail, holding the international conference calls, the ones distributing the films, controlling the news, organizing the investments and the international currency transactions. These are the groups who are really in a sense in charge of timespace compression, who can really use it and turn it to advantage, whose power and influence it very definitely increases (1991: 149). 
Written in 1991, the power-geometries described here by Massey could (with the mention of email aside) have been set in a period as early as the 1960s, or earlier-long before the nexus of neoliberal globalization and the ICT revolution upset this somewhat schematic process radically. Today, the geometries of power in the network society are in deep flux, and accordingly, the historical sureties of power concentration are no longer so straightforward. The essences of neoliberalism such a economic deregulation, market rule and the unfettered application of ICTs have meant that the relationships of power that have underpinned not only capitalism, but much of modern culture and society, have been thrown up into the air. Time-space compression plus the creation of a network ecology through mass participation by hundreds of millions of users have dissipated these grid-like "Fordist" geometries that Massey describes, and they are up for grabs. In the network, power no longer congeals so persistently around its historical geometries. In the information order, as Scott Lash notes, "power is elsewhere" (2002:75).

Network time, or what others (e.g., Lee 1999) have called "polychronicity" already undermines (unintentionally, it must be added) the rigid power time of capitalism. For example, Failla and Bagnara (1992, cited in Lee and Liebenau 2001: 49) argue that the application of ICTs:

...generates work methods that cut across the "traditional" sequence of events, changing the durations customarily regarded as "appropriate" and reducing the need to ...resort to rigid timetables. The effect of these changes is to disrupt the traditional work rhythms. In this sense [ICTs] help to eliminate or diminish the importance of time frames generally accepted as appropriate for performing a given activity.

The authors see this in positive terms, causing decision-making and work rhythms to be more flexible, giving people more time (and more flexible time) as the rigid time-frames of Fordist capitalism are "disrupted." Other observers who argue not necessarily from the perspective of neoliberal capitalism also see this as a good thing; it's a win-win situation indeed, for employers, for employees and for the built environment, too (Florida, 2002). The network society that has evolved out of the nexus between neoliberal globalization and the ICT revolution, however, has ensured that no one "wins." Let us look briefly at the time practices of ordinary people in the network society, before looking at the larger, systemic picture. An empirical investigation into the time practices of people by Dale Southerton (2003) has shown a growing anxiety experienced by those who feel a "time squeeze." The disruption of Fordist time frames through neoliberal/ICT-induced flexibilization has left personal control over time, for most people, even more diminished. The blurring of work time and family/leisure time force people to rationalize their time allocating and time coordinating practices, causing them to feel constantly "rushed" or "harried" (Southerton, 2003). In her best-selling study The Time Bind (1997), Arlie Hochschild makes a similar case. Clearly, instead of a "win" situation, most people feel compelled to synchronize themselves (or constantly try) to the "polychronicity" of the network.

The revolutions of neoliberalism and ICTs have certainly made capitalism flexible, and have disrupted the old time-grids of Fordism, but at a cost that will probably be unsustainable over the long term. In other words, capitalism, through its revolutionary momentum, in a systemic dialectic, is digging its own grave-again. Massey, in the quote above, writes of those "groups who are really in a sense in charge of time-space compression." As I said before, however, these words could have been written in the 1960s, long before the rise of the network society, and long before the power of those "groups" became problematic. On the effects of neoliberal globalization, Anthony Giddens (1997: 4-5) has written that:

We are at the beginning of a fundamental shakeout of world society, which comes from numerous sources... It comes from the impact of technology on global markets and also from the disappearance of the Soviet Union. We are at the beginning of this process and we don't really know as yet where it is going to lead us... If you could say that the West controlled the earlier phases of globalisation, the current phase is one that nobody controls. (emphasis added)

Certain individuals and groups benefit from this upset power-geometry. Some, of course, get to become extremely powerful. But no one is in control because the power geometry that rested upon the spatial and temporal grids of Fordist capitalism has been shattered by neoliberalism and the ICT revolution. Harvey's "rapidity of time" does indeed make it increasingly difficult to "react to events." Planning and consolidation of power count for less when "events" can hit like a tidal wave. Wild stock market fluctuations, the deregulation of industries, the diminution of regulatory government involvement in all aspects of the economy (let the market decide) has meant that individuals and groups leading a company one day can find themselves and their corporations in deep trouble the next (like the CEOs of Enron and WorldCom). The effect of the neoliberal globalization/ICT revolutions, then, does make 
capitalism more flexible, it does disrupt the temporal grids of Fordism-but it also disrupts the power-geometry that was formed upon these. A flexible and informationized capitalism is, then, over the medium- to long-term, a much weaker and intrinsically risk-prone capitalism.

\title{
| The New Times of Postmodernity?
}

Power time has been undermined, but potential timescapes of diversity have not filled the vacuum. Flux, risk and uncertainty are still the defining characteristics of the neoliberal network society. However, within this dis-order lie immense opportunities for individuals and groups seeking to achieve more autonomy and sovereignty in the spaces and times of the network. Democratic potential, like potential timescapes, is immanent in the network. Within the flux of the network, new power-geometry formations are possible, and dense levels of interconnectivity are the basis for this. Millions of people, what Hardt and Negri (2000) term the "multitude" as opposed to "the people"as connected individuals or as part of groups_are already working against the alienating logic of the neoliberal globalization/ICT nexus. The most important development here is that they are using the network and its multiform ICT applications to achieve this. For instance, shadowing the growing scope and scale of the network society since at least the mid-1990s, has been its antithesis, the so-called "global civil society movement" (Graeber 2002; Klein 2002). This is a broad coalition that ranges from middle-class church groups, environmentalists of every class strata, trades unionists, well as ordinary people from all walks of life who feel the erosion of civil society to be retrogressive, unfair or simply "wrong" in some unspecified way. What unites these is a deep-seated antipathy to the logic of neoliberalism and the free market. What enables them to organize together is their shared recognition that the network society is here to stay, and that ICTs, not parliamentary politics or the ways of a now-corrupted civil society, can be the tools of change. They share the idea that if used democratically, used primarily for people and not profit, then new ideas, new knowledges, new ways of being and new ways of seeing can take hold and transform the neoliberalized and rationalized network society into a more fair and sustainable one.

Digital networks, by their very nature (dense interconnectivity), are the perfect platform for this. They have the potential for the construction of new power-geometries that are both democratic and inclusive. Douglas Kellner (2002) and others have dubbed it a "technopolitics" and it has emerged as an alternative to the sterile politics of neoliberalism and the alienating network society it has created. As Michael Hardt (2002: 117) has written on the contradictory stance that the global civil society movement has take vis-à-vis traditional party politics and their exclusive power-geometries:

\begin{abstract}
The traditional parties and centralized organizations have spokespeople who represent them and conduct their battles, but no one speaks for a network. How do you argue with a network? The movements organized within them do exert their power, but they do not proceed through oppositions. One of the basic characteristics of the network form is that no two nodes face each other in contradiction; rather, they are always triangulated by a third, and then a fourth, and then by an indefinite number of others in the web.
\end{abstract}

Hardt articulates nicely here the potential democratic power of the "web" over the "grid"; and through the web, the global civil society movement has emerged as a pointer to the ways in which the rule of neoliberalism and the currently rationalized network society may be challenged. In terms of these newly evolving power-geometries, people, through the network, derive their power from each other in a flexible and inclusive web of digital interaction. And as users of technologies within an open web, people and groups are able, potentially at least, to learn to become both "culturally competent" (Fiske, 1987) and technologically sophisticated. That is to say, they become skilled in the use of ICT applications and devices, and are able to situate their use within the larger cultural context in a way that is self-empowering instead of self-alienating (Hassan 2004). It is through such a relationship with ICTs that the basic elements of network autonomy and sovereignty may be built up and built upon. Through the actions of people as users, the network, as we have seen, generates its own time, network time. This network temporality, to be sure, is accelerated if taken as a networked whole. This is primarily because most people still do not exert real autonomy over their ICT use in the context of the network society. They have not yet managed (or have yet attempted) to connect a "cultural competence" with a "techno savvy." Most of us still feel time pressured and feel that the network society has contributed primarily to the "acceleration of just about everything," as Gleick (2000) put it.

Nonetheless, the truly revolutionary thing about the information technology revolution and the network society 
it is rapidly constructing may be something social science has not yet given much thought to-the creation of a new form of time and a new relationship with temporality. When we speak of "revolution" it is also important to remember that we are not dealing with a cataclysmic break with what went before. As Karl Marx well understood, revolutions never are. He saw the past in terms of continuities in ideas, in traditions that carry forward and help shape the future. Marx, however, saw this in somewhat negative terms, as serving to blunt the revolutionary ardor of the workers, causing them to be timid and fearful of their true potential. Revolutionary socialism is not on the agenda today; but the overthrow of capitalism is not necessary to move to a new digital phase of increased democracy and social justice. The global civil society movement is only one example of what is possible when people, through a developing of continuities from past practices, are able to gain a measure of autonomy over ICTs within the information order. The radical essence of network time is that capitalism, and, therefore, society can become (and is already becoming) disconnected from the tyranny of the unerring meter of the clock and the temporal domination it has developed over the last two hundred years and more. Accordingly, through the self-conscious creation of different timescapes—-to be intentionally "untimely," for example, as McKenzie Wark (2001) put it—means that people themselves, acting as part of a movement, or as individuals, can undermine the neoliberal order that shapes the network society today. They are therefore able to play a part to help shift capitalism onto another temporal and organizational plane, one where the democratic timescapes of communities, of production and consumption and of the diverse particularities of context and culture can transform capitalism into something more humanistic. Capitalism can therefore be a mode of production that is constitutive of a multiplicity of temporalities and of timescapes, ones that are more in synchrony with the needs and aspirations of users as autonomous agents within an open and fluid networked whole.

Éric Alliez, in the quotation I cited above, argued that capitalism couldn't exist without the abstract and totalitarian meter of clock time. The evolution of the network society has shown (in potential at least) that it can. Moreover, it can be a mode of production where-once freed of the temporal constrictions of neoliberalism and its fetish for instrumentalized speed and technological "efficiencies"- the dischrony and risk that it generates can become more harmonized, and the temporalities of power time and potential time less rigidly opposed to each other. In short it can be a temporally diverse and timescape-rich network society where hundreds of millions of culturally competent and technologically savvy users of ICTs can shape it into something(s) we haven't yet dreamed of.

\section{References}

Adam, Barbara. 1995. Timewatch. Cambridge, UK: Polity Press. -.-. 1998. Timescapes of Modernity: The Environment and Invisible Hazards. London, UK: Routledge.

-.-. 1999. "Industrial Food for Thought: Timescapes of Risk." Environmental Values, 8/2: 219-238.

---. 2003. "Reflexive Modernization Temporalized." Theory, Culture \& Society Vol. 20(2) Pp.59-78.

---. 2004. Time. Cambridge, UK: Polity Press.

Alliez, Éric. 1996. Capital Times: Tales From the Conquest of

Time. Minneapolis, MN: University of Minnesota Press.

Appadurai, Arjun. 1990. "Disjuncture and Difference in the Global Cultural Economy” in Public Culture. Vol.2 No. 2: $1-24$.

Bauman, Zygmunt. 1998. Globalization: The Human Consequences. Cambridge, UK: Polity Press.

Brumfeil, Geoff. 2001. "Nanocomputers Get Real.” Wired Magazine. November 9th.w

Castells, Manuel. 1996. The Information Age: Economy, Society and Culture. Oxford, UK: Blackwell.
Fiske, Jon. 1987. Television Culture. London, UK: Methuen. Flaherty, Michael. 1999. A Watched Pot: How We Experience Time. New York: New York University Press.

Florida, Richard. 2001. The Rise of the Creative Class. New York: Basic Books.

Giddens, Anthony. 1997. "Excepts from a Keynote address at the UNRISD Conference on Globalization and Citizenship" UNRISD News. 15: 4-5.

Gleick, James. 1999. Faster: The Acceleration of Just About Everything. New York: Abacus.

Gosden, Christopher. 1994. Social Being and Time. Oxford, UK: Blackwell.

Graeber, David. 2002. "For a New Anarchism” New Left Review. 13, January-February: 61-73.

Haas, Robert. 1994. The Essential Haiku. New York: Ecco Press. Habermas, Jürgen. 1987. The Theory of Communicative Action. Vol. 2. Boston: Beacon.

Harvey, David. 1989. The Condition of Postmodernity. Oxford, UK: Blackwell. 
Hassan, Robert. 2003. The Chronoscopic Society: Globalization, Time and Knowledge in the Network Economy. New York: Lang.

---- 2004. Media, Politics and the Network Society. Buckingham, UK: Open University Press.

Hardt, Michael. and Negri, Antonio. 2000. Empire. Cambridge, Mass.: Harvard University Press.

Hardt, Michael. 2002. “Porto Alegre: Today's Bandung?” New Left Review. 14, March-April: 112-118.

Heim, Michael. 1993. The Metaphysics of Virtual Reality. New York: Oxford University Press.

Hochschild, Arlie. 1997. The Time Bind. New York: Metropolitan Books.

Kellner, Douglas. 2002. "Globalization, Technopolitics and Revolution.” http://www.gseis.ucla.edu/faculty/kellner/ papers/GlobTPRev-Foran.htm Accessed 24 November 2003

Klein, Naomi. 2002. Fences and Windows. London, UK: Flamingo.

Lash, Scott. 2002. Critique of Information. London, UK: Sage.

Lee, Heejin. 1999. "Time and information technology: Monochronicity, polychronicity and temporal symmetry." European Journal of Information Systems 8: 16-26.

Lee, Heejin and Liebenau, Jonathan. 2001. "Time and the Internet." Time \& Society. 9 (1): 43-56.

Lefebvre, Henri. 1991. The Production of Space. Oxford, UK: Blackwell.

Lukacs, Georg. 1990. History and Class Consciousness. London, UK: Merlin Press.

Massey, Doreen. 1994. "A Global Sense of Place" in Space, Place and Gender. Pp.146-156. Edited by Doreen Massey Cambridge, UK: Polity Press.
MIT News. 2001. "NSF awards $\$ 13.75 \mathrm{M}$ to MIT Media Lab to create Center for Bits and Atoms" http://web.mit.edu/newsoffice/nr/2001/bitsandatoms.html, Accessed 14 August 2003.

Mumford, Lewis. [1934] 1967. Technics and Civilization. London, UK: Routledge and Kagan Paul.

Omahe, Kenichi. 1993. The End of the Nation State. New York: Free Press.

Prendergast, Christopher 2003. “Codeword Modernity” New Left Review 24 November-December 2003, Pp. 95-111.

Robertson, Roland. 1992. Globalization: Social Theory and Global Culture. London, UK: Sage.

Sawhney, Harmeet. 2004. "The Slide towards Decentralization: Clock \& Computer” Media, Culture and Society Vol. 26 No. 3 Pp. 359-375.

Southerton, Dale. 2003. “Squeezing Time” Time \& Society Vol. 12 Number 1, Pp. 5-25.

Steger, Manfred. 2002. Globalism: The New Market Ideology. New York: Rowman and Littlefield.

Wark, McKenzie. 2001. “Abstraction” Fibreculture. Edited by Hugh Brown et al, Melbourne, Australia: Arena Publishing.

Virilio, Paul. 1986. Speed and Politics. New York: Semiotext(e)

---. 1997. Open Sky. London, UK: Verso.

-.--. 2000. The Information Bomb. New York: Verso.

Waters, Michael. 1995. Globalization. Cambridge, UK: Polity Press.

Whitrow, G. J. 1972. What Is Time?. London, UK: Thames and Hudson. 